\title{
SÖZLÜ KÜLTÜRDEN YAZILI KÜLTÜRE KITTAPTAN EKRANA: LEYLÂ VE MECNUN
}

\author{
FROM ORAL CULTURE TO WRITTEN CULTURE FROM BOOK TO SCREEN: \\ LEYLÂ AND MECNUN
}

\section{Mehmet ÖZDEMİ*}

\begin{abstract}
ÖZ: Anlatı, insanoğlunun yaşantı, hayal ve kurmaca boyutuyla coğrafyalar arasında aktarımda bulunduğu hikâyelerin ortak adıdır. Hikâyenin çekirdeği çoğu zaman yașanmıș veya yașanması muhtemel bir olaya bağlanmaktadır. Bu bağlamda bazı anlatılar, doğduğu kökenden aldığı güçle evrensel bir karakter kazanmaktadır. Bu çalışmada Leylâ ve Mecnun efsanesinin geçmişi ile bugünü; mesnevî, halk hikâyesi, roman, tiyatro, kapsamında yazılı kültür verileri ile radyo, televizyon, sinema ve internet üzerinden dijital ortamdaki durumu incelenmektedir. Arap kaynaklı bir efsane olan Leyla ve Mecnun, Türk kültür ikliminde kendisine özgü ve özgün bir kültürel mirasa dönüșmüștür. Leylâ ve Mecnun'un kökeni, Divan edebiyatındaki yükselişi ve modern edebiyata olan yansımaları yanında perdeye ve ekrana aktarımı da çözümlenmeye ihtiyaç duyulan konular arasındadır. Leylâ ve Mecnun, sadece Divan edebiyatındaki çalışmalarla sınırlı kalmamıştır; başta romanlara, sonra şiir kitaplarına ve karikatürlere konu olmuştur. Bu aşk trajedisi popüler edebiyata, tiyatroya, sinema ve internet bağlamına da önemli bir birikim olarak aktarılmıştır. Dolayısıyla bu çalışmada Leylâ ve Mecnun hikâyesi hakkında sözlü, yazılı, işitsel, görsel ve dijital içeriklerden hareketle analitik çözümlemeler yapılmıştır.
\end{abstract}

Anahtar Kelimeler: Sözlü kültür, yazılı kültür, dijital kültür, hikâye, Leyla ve Mecnun.

ABSTRACT: The narrative is the common name of the stories that humanity transfers between the dimensions of life, imagination and fiction, and geographies. The core of the story is often connected to an event that has happened or is likely to happen. In this context, some narratives gain a universal character with the power they derive from the origin of their birth. In this study, the past and present of the legend of Leylâ and Mecnun; the mathnawi, folk story, novel, theater, culture data written in the context and the status of digital media over radio, television, cinema and internet are examined. Leyla and Mecnun, an Arab-origin legend, have turned into a unique cultural heritage in the Turkish cultural climate. The origins of Leylâ and Mecnun, the rise in Divan literature and its reflections on modern literature, as well as its transfer to curtain and screen are among the issues that need to be resolved. Leylâ and Mecnun were not only limited to studies in Divan literature; It was primarily the subject of novels, poetry books and caricatures. This love tragedy has been cited as an important accumulation in popular literature, theater, cinema and the Internet. Therefore, in this study, analytical examinations were made about the story of Leylâ and Mecnun based on verbal, written, audio, visual and digital contents.

Keywords: Oral culture, written culture, digital culture, story, Leylâ and Mecnun.

\footnotetext{
${ }^{*}$ Dr. Öğretim Üyesi - Artvin Çoruh Üniversitesi Fen-Edebiyat Fakültesi Türk Dili ve Edebiyatı Bölümü / Artvin - mehmet_ozdemir@outlook.com.tr (ORCID ID: 0000-0002-9046-4735) 


\section{Giriş}

Anlatım esasına dayalı edebi eserler, tematik bakımdan konularına göre kahramanlık ve aşk hikâyeleri olarak iki kolda incelenmektedir. Söz konusu anlatılar, mit, efsane, masal, destan vb. gibi türleri besleyen önemli kaynaklardır. Bu anlatılar dönemin şartlarına göre bağlamlar arası ve icralar arası etkileşimlerle bugüne kadar yaşatılmıştır. Hemen her dönemde başta okuyucular olmak üzere; dinleyici ve izleyici de aktif bir şekilde anlatım türleriyle ilgilenmiștir. Bu kapsamda Leylâ ve Mecnun anlatılarında1 okuyucuyu, dinleyiciyi ve izleyiciyi kendisine çeken önemli temalar, hayaller, trajedi, kara sevda, aşk, tutku, popüler kültür bağlamında ise mizahtır.

Kültürleri birleștiren ana olgulardan bir tanesi de aşk duygusudur. Aşk, gerek beșeri gerek ilahi boyutuyla edebi eserlerin önemli temaları arasında yer almaktadır. Mehmet Törenek'e göre “Gönülden kaynağını alan ve karşı cinsler arasında bir gönül bağı, bir cazibe, bir hâkim duygu olarak varlığını sürdüren aşk, ferde bağlı oluşu yönüyle ezeli bir duygudur. Bu yönüyle insanlığın ortak duygusu olduğu gibi, ortak teması da olmuştur" (1999: 181). Yüzyıllardır “...umutsuz aşk, karşılıksız aşk, yasak aşk...” (Özyön, 2013: 24) pek çok kültürün en bilinen ve aktarılan hikâyelerinin ana temasını oluşturmuştur. Aşk, zaman ve mekân tanımaz; onun evrenselliği ıstıraplarla yüklü olmasından gelir. Fuzulî’nin Leylâ ve Mecnun mesnevisinde görülen imkânsız aşk tutkusu, Leylâ'dan Mevla'ya doğrudur. Burada resmedilen Leylâ karakterinde Allah'ın sıfatları, Mecnun'da ise yaratanı arayan, arzulayan ve bu yolda mücadele verip zorluklara gögüs gerenler anlatılmaktadır (Doğan, 2010: 12). Nitekim Mecnun, Behçet Mahir'den derlenen Leylâ ile Mecnun hikâyesinin sonunda Leylâ'yı ararken Mevlâ'yı bulduğunu anlatan bir türkü okumaktadır (Sakaoğlu vd. 1999: 153). Dolayısıyla Leylâ ve Mecnun hikâyelerinin genel karakteristiği beșeri aşktan tasavvufi aşka yönelim şeklindedir.

Edebi metinlerde kahramanlar, zaman, mekân, olay örgüsü ve türler değişse de aşk duygusu işlenmeye devam etmiştir. Doğu ve Batı edebiyatı incelendiğinde ıstıraplı aşk öykülerinin insanlar üzerinde derin etkiler bıraktığı görülmektedir. İmkânsız aşk temasını işleyen anlatılar arasında halk hikâyeleri ile romanlar önemli bir mevkii işgal etmektedir. Leylâ ile Mecnun, Kerem ile Aslı, Ferhat ile Şirin hikâyelerinde olduğu gibi Goethe'nin Genç Werther'in Acıları, Stendhal'ın Kırmızı ve Siyah, Flaubert'in Madame Bovary, Emile Zola'nın Therese Raquin, Halit Ziya Uşaklıgil'in Aşk-ı Memnu, Mehmet Rauf'un Eylül, Peyami Safa'nın Fatih Harbiye, Reşat Nuri Güntekin'in Yaprak Dökümü, vb. gibi romanlarda aşkın farklı yönleriyle karşılaşılmaktadır.

\footnotetext{
${ }^{1}$ Leylâ ve Mecnun'un sadece hikâye olarak değil birçok türde ele alınmasından dolayı bu kavram tercih edilmiştir.
} 
Edebi metinler incelendiğinde aşkın platonik, mistik ve gerçeklik bağlamında işlendiği görülmektedir. Sözü edilen bu duygu, genel itibariyle mutlu sonla bitmez. Așkta vuslat değil hasret sunulmaktadır. Edebiyat eserlerinin söz konusu bu trajedisi, okuyucuyu derinden etkilemektedir. Geçmişte okuyucuyla eser arasında aracılık görevini yerine getiren en önemli iletişim aracı yazı ve buna bağlı olarak ortaya çıkan kitap, gazete ve dergi olmuştur. Daha sonra radyo ve televizyon bu görevi yoğun bir şekilde üstlenmiștir (Aytaç, 2005: 9). Bu iletişim araçlarına ilaveten günümüzde ise internet, kültür ve edebiyatın aktarımı görevini üstlenmiştir. Tüm bu iletişim araçları popüler kültür ortamında işlevsel bir biçimde çalışmaktadır. Bilindiği gibi popüler kültürün en önemli işlevi tüketimi teşvik etmesidir. Bu doğrultuda birtakım araçlardan (medya-internet-sinema ve yazılı basın) yararlanır. Popüler kültürde "edebiyat eserinin medya kapsamında farklı ürünlere dönüștürülmesi” (Özdemir, 2008: 15) kültürel süreklilik ve metinlerarasılık olarak değerlendirilebilir. Popüler kültür, sözü edilen bu tüketim amacına ulaşmak için geleneği yeniden üretme sürecine başvurur. Folklor ürününün değişmesi, çeşitlenmesi ve varyantlarının oluşması esasında sürekliliğin bir gereğidir (Aktulum, 2013: 9). Bu anlamda folklorun ortaya çıktığı ilk haliyle (urform) değil de çağın koşullarına göre yeniden ele alınması geleneğin ve geleneksel olanın yaşatılması bakımından son derece önemlidir. $\mathrm{Bu}$ anlamda günümüz toplumlarının ihtiyaç ve beklentisi, geleneksel anlatıların sözlü, yazıll, görsel, işitsel vb. yönlerden işlenmesi gerekliliğini doğrulamaktadır.

Hangi zaman ve mekânda yazılırsa yazılsın, beğenilen bir aşk hikâyesi, birbirinden farklı yazarların kaleminde çeşitli kahramanların sunumuyla romanlara, tiyatroya yansitılırken yönetmenlerin objektifinden televizyona ve sinemaya aktarılmaktadır. Ancak burada unutulmaması gereken her metnin bir ön metin üzerine kurulmuş olmasıdır (Ong, 2010: 190). Bunun bir sonucu olarak "okuyucular, dinleyiciler ve seyirciler her bir medyadan (kitap, radyo, film ve televizyon) farklı tatlar alırlar" (Aytaç, 2005: 20). Efsanevî veya gerçek olsun trajik aşk öyküleri sadece belli bir dönemde okunan ve belleklerde yaşatılan eserler olarak kalmamakta dönemin okuyucusunun ve izleyicisinin ihtiyaçlarına göre modern kültür aktörleri tarafından kültürel ekonomik içeriklere dönüştürülerek yeniden üretilmektedir. Burada tek yönlü bir bakışla kitaptan okumak anlayışı kısmen de olsa terk edilmektedir. Söz konusu süreç metnin radyodan dinlemesi, perdeler halinde tiyatro sahnesinde yer alması, birkaç sezonluk diziler halinde televizyona aktarılması veya yönetmenlerin elinde sinema filmine dönüşmesi şeklinde işlemektedir. Dolayısıyla makalede söz konusu hikâyenin efsanevi kurgusundan hareketle kitaplara, sahneye, radyoya, ekrana ve perdeye aktarımı konusu çeşitli yönlerden dikkate sunulmaktadır.

Batı edebiyatında Romeo ve Juliet'in paylaşılan trajedisi, onun evrenselliğini tetiklemiştir. Romeo ve Juliet bu yönüyle kültürel ekonomik bir içeriğe dönüşerek İngiliz kültürünü dünya geneline taşıyan önemli bir bayrak olmuştur. Dolayısıyla Romeo ve Juliet bir tiyatro metni olmanın 
dışında, pek çok alanda dünyaya sesini duyuran önemli bir aşk öyküsü olarak değerlendirilmektedir. ${ }^{2}$ Eserin opera ve sinemadaki zengin sunumları, tiyatro sahnesindeki gösterimleri aratmamıştır. Pek çok yazarın çözümlemelerinde temel referans konumuna yükselmiştir. Bu açıdan bir ekol haline gelen eser, sahnede ve ekranda güçlü temsiller bulmuştur. Günümüz popüler kültür çağında söz konusu durumun pek çok örneğiyle karşılaşmak mümkündür. Yönetmenler geçmişin mirasını kendi yorumlarıyla kitaptan ekranlara yansıtma yolunu tercih etmişlerdir.

Türkiye'de kitaptan ekrana yansıyan ilk eser Aziz Nesin'e aittir (Şentürk, 2012; URL-18). Aziz Nesin, Yaşar Ne Yaşar Ne Yaşamaz'ı radyo oyunu olarak yazmıştır. Kazandığı başarı sonucu tiyatro sahnesine uyarlanan eser, sinemaya da aktarılmıștır. Nesin'in "Yaşar Ne Yaşar Ne Yaşamaz" isimli eseri 1974 yılında başrolde Halit Akçatepe'nin oynadığı, Engin Orbey senaristliğinde sinemaya uyarlanmıștır.3 Aynı eser, 2008 yılında Şafak Sezer'in başrolde oynadığı, Ulaş ve Atıl İnaç'ın yönetmenliğini yaptığı başka bir sinema filmiyle izleyiciyle buluşmuştur. Söz konusu eser Kenan Işık tarafından iki perdeden oluşan müzikli oyun şeklinde sahneye uyarlanarak İstanbul Büyükşehir Belediyesi Şehir Tiyatroları'nda sahnelenmiştir.

Kitaptan ekrana yansıtılan eserlerden bir kaçı şu şekilde sıralanabilir: Sait Faik, "Kumpanya", Ömer Seyfettin, "Topuz, Diyet, Ferman, Pembe Incili Kaftan", Necati Cumalı, "Susuz Yaz", Abbas Sayar, "Yllkı Atı", Hüseyin Rahmi Gürpınar, "Şıpsevdi", Necip Fazll, "Bir Adam Yaratmak", Kemal Tahir, "Yorgun Savaşçı" (Şentürk, 2012; URL-18), Reşat Nuri Güntekin, "Çalıkuşu, Dudaktan Kalbe, Yaprak Dökümü", Halit Ziya Uşaklıgil, "Așk-ı Memnu", Orhan Kemal, "Hanımın Çiftliği", Şule Yüksel Şenler, "Huzur Sokağı", Halide Edip Adıvar, "Kalp Ağrısı", Peyami Safa, "Fatih Harbiye" Fakir Baykurt, "Yllanların Öcü". Romanların diziler halinde televizyona aktarılması birtakım olumlu gelişmeler de sağlamaktadır. Çoğu unutulmaya yüz tutan eserler, dizileri çekilen romanlar serisi olarak ün yapmış ve yeniden okuyucuyla buluşma fırsatı bulmuştur. ${ }^{4}$ Türk sineması ilk yıllarda özgün senaryolar yerine tiyatro ve edebiyat eserlerinden yararlanmıştır. Halk hikâyelerinden uyarlanan ilk film Adolf Körner tarafından 1942 yılında çekilen Kerem ile Aslı olmuştur. Sonraki yıllarda Köroğlu destanından yapılan uyarlamalar kayda değerdir. 1952 yılında Ömer Lütfi Akad adeta bir çığır açarak Tahir ile Zühre, Arzu ile Kamber hikâyelerini filme almıștır. Daha sonraki yıllarda Ferhat ile Şirin, Leylâ ve Mecnun hikâyelerinin filmleri çekilmiştir (Alıç, 2011: 20-21).

\footnotetext{
2 William Shakespeare tarafından yazılan Romeo ve Juliet, bir tiyatro oyunu olmanın ötesinde imkânsız aşk öykülerinin simgesi ve en çok tekrar eden örneklerinden birisi olarak tipleşmiştir. Romeo ve Juliet, telif eser çevrileri dışında, sahne gösterileri, film uyarlamaları, müzikler vb. gibi türlerde kültürel ekonomik içeriklere dönüşmüștür. Ayrıca bk. (ULR-1).

${ }^{3}$ Bu konuda ayrica bk. (URL-2).

4 Türk sinemasında film olan eserler için ayrıca bk. (Alıç, 2011: 22-23; Özdemir, 2008: 163187).
} 


\section{Kuşaklar ve Türler Arası Bir Anlatı: Leylâ ve Mecnun}

Leylâ ve Mecnun esas itibariyle Arap çöllerinde vücut bulmuş bir efsanedir. Arap kaynaklı olan bu çile ve ıstırap yüklü aşk hikâyesi İran ve Türk edebiyatında kendine önemli bir yer bulmuştur. Özellikle Türk edebiyatında Leylâ ve Mecnun, en çok yazılan mesneviler arasında yer almıştır. Edebiyat tarihçilerine göre Fuzulî'nin Leylâ ve Mecnun'u bu mesnevilerden en başarılı olanıdır. Fuzulî, Leylâ ve Mecnun'u yazarken onu tasavvufun duyguları coşturan ve insan ruhunu kanatlandıran açılımları ile yoğurmuş, bambaşka bir güzellikle takdim etmiş ve beşeri özü korumayı bilmiştir. Onun başarısı ve insanı gerçekten etkileyen samimiyeti, Leylâ ve Mecnun'u bütün dünya edebiyatlarının nitelikli eserleri arasında yukarılara taşımıştır (Doğan, 2010: 11-12).

Türk edebiyatında XV. yüzyıldan itibaren işlenmeye başlanan Leylâ ve Mecnun aşkı, ilk başlarda İran etkisinde bir çizgi takip etmiştir. Bu mirasın önemi zamanla anlaşılmış ve Türk şairleri de Leylâ ve Mecnun'da kendi çizgilerini bulmuşlardır. Osmanlı sahasında Edirneli Şahidî, Çağatay sahasında ise Ali Şir Nevayî, Leylâ ve Mecnun konusunu işleyen en eski şairlerdir. Leylâ ve Mecnun konusunu İran edebiyatında "Genceli Nizamî, Emir Hüsrev-i Dehlevî, Abdurrahman-ı Camî, Âtifî"; Türk edebiyatında "Şahidî, Nevayî, Bihiştî, Hamdullah Hamdî, Ahmed Rıdvan, Kadimî, Celilî, Sevdayî, Hakirî, Fuzulî, Lârendeli Hamdî, Halife, Atayî, Faizî, Örfî, Andelîb ve Nâkâm" gibi şairler işlemiştir (Doğan, 2010: 11). Türk edebiyatında Ali Şir Nevâî, Fuzulî ve Hamdullah Hamdî̀nin Leylâ ve Mecnun mesnevileri oldukça ün kazanmıștır (Pala, 2011: 289).

Leylâ ve Mecnun aşkı ilmi çözümlemelere göre tasavvufî bir aşk olarak yorumlansa da halk arasındaki inanışa göre birbirini seven; ama bir türlü kavuşamayan, kara sevdalı iki gencin çileli aşklarının öyküsüdür. Leylâ ve Mecnun, Divan edebiyatında şairleri birbirileriyle boy ölçüştüren önemli bir temadır. Mükemmel mesnevi yazma tutkusu, pek çok Divan şairini bu konuyu işlemeye itmiștir. Leylâ ve Mecnun'un Divan edebiyatında zengin bir şekilde işlenmesi, onu aşk mesnevileri içerisinde ilk sıralara taşımıştır. Fuzulî, kendisinden önce bu hikâyenin Türkler arasında bulunmadığını söylemiştir: "Leylî Mecnûn Acemde çohdur / Etrâkde ol fesâne yohdur5" (Doğan, 2010: 104). Ancak Leylâ ve Mecnun Türkçe'ye Fuzulî'den önce kazandırılmıștır. ${ }^{6}$

Fuzulî’nin amacı yaşadığı devirde bilinen, sevilen bu efsanevî aşk hikâyesini en güzel şekilde ele alarak yeni bir soluk getirmektir. Fuzulî, Leylâ

\footnotetext{
5 Günümüz Türkçesi: “Leylâ-Mecnun, Acemlerde çoktur, lakin Türkler arasında bu hikâye bulunmuyor" (Doğan, 2010: 105).

${ }^{6}$ Bu konuda Muhammet Nur Doğan şu tespite ulaşmıştır: "Fuzulî, 'Leylâ ve Mecnun, Türkler arasında hiç yoktur' derken, kendinden önce Türkçe olarak Leylâ ve Mecnun'lar yazılmış olduğundan tamamen habersiz gözükmektedir. Hâlbuki bu hikâyeyi Türkçe'de ilk defa, XV. Yüzyılda Ali Şîr Nevayî yazmış; aynı efsane Fuzulî’den önce Celilî ve Sevdaî tarafından da Türkçe olarak kaleme alınmıștır" (2010: 13).
} 
ve Mecnun hikâyesine yeniden can vermek istemiștir. "Takrîre getür bu dâstânı / Kll tâze bu eski bûstânı" (Doğan, 2010: 104). Ancak Leylâ ve Mecnun hikâyesini yazmak kolay değildir. Fuzulî zor bir ișe kalkıştığının bilincindedir; ama başarılı olacağına da inanmaktadır. Nitekim Fuzulî "Ta'mîr-i harâba tâlibem men / İnşâallâh gâlibem men8" diyerek mesnevinin dibacesinde (önsöz) bu durumu şu şekilde özetlemiştir:

"Ve eğer bu şaşkın fakir, sefil Fuzulî, bilgi sermayesi yoksunluğunun son haddinde ve fesahat emtiası noksanlığının en son ucunda hakikat erbabı arasına girme talebinde bulunup, ince nükte sahipleri dizisinin arasına sokulma cüretinde bulunarak Leylâ'nın güzelliği hikâyesini yazma işinin üstesinden gelmeye ve Mecnun'un aşkı harabesinin tamirine gayret ediyorsa; beklenti odur ki; o kalem üslubu ve yazı tarzı en güzel bir şekilde gerçekleşip, Leylâ hikâyesi gibi cihanı tutsun ve Mecnun'un aşkı gibi sonsuzluğa ulaşsın..." (Doğan, 2010: 25).

Fuzulî'nin kaleminden adeta kendisini bulan ve zirve noktaya ulaşan Leylâ ve Mecnun hikâyesinin bugünkü şöhretini söz konusu kültürel mirasa borçlu olduğu söylenebilir. Bu hikâyenin başarılı örneklerinin Divan edebiyatı çevresinde oluştuğu doğrudur. Ancak Leylâ ve Mecnun sadece Divan edebiyatıyla sınırlı bir tema olarak görülmemelidir. Leylâ ve Mecnun âşıklar ve meddahlar tarafından halk hikâyesi yapısına uygun olarak anlatılan önemli hikâyelerden birisidir. Klasik edebiyattaki tematik kurguya benzer bir seyirle halk hikâyesi yapısında icra edilmiştir. Leylâ ve Mecnun ayrıca popüler edebiyatta tiyatro, öykü ve roman, sahnede piyes, perdede sinema filmi, radyoda oyun, ekranda dizi, internette skeç, reklam, karikatür, parodi vb. türlerde değişim ve dönüşümler geçirerek yeniden ele alınmıştır. Dolayısıyla kaynağını Arap çöllerinden ve efsanesinden alan Leylâ ve Mecnun, günümüze değin çok türlü bir oluşum süreci geçirerek varlığını korumuştur. Hangi kültürde olursa olsun karşılaştırmalı edebiyat alanında en önemli malzemelerden bir tanesi de edebiyat eserlerinin birbirinden etkilenmesidir. Özellikle çileli aşk öyküleri, edebiyat eserlerinde ana temalardan olmuş ve bu öyküler yeni oluşturulan eserlerin en önemli telmih kaynakları arasında yer almıştır. Nice şair ve yazar, Kerem ile Aslı'yı, Âşık Garip ile Şah Senem'i, Arzu ile Kamber'i, Leylâ ve Mecnun'u eserlerinde yeniden canlandırdığı gibi, aynı zamanda başka aşk hikâyelerine de referans göstermiştir.

Medya, pek çok alanda olduğu gibi -günümüzde varlığı yadsınamayacak ölçüde- geleneksel olanın sunumunda da önemli bir araçtır. Bu bağlamda "...Türk medyası fikra, makale, röportaj, karikatür, fotoğraf, mektup, ilan, reklam, haber, dizi, belgesel, radyo oyunu gibi ürünleri, Türk kültür belleğine ait farklı gelenekler ve unsurları ortaya koyabilmektedir (Özdemir, 2008: 13). Geçmişte edebiyat eserleri için kahraman yaratmak ön

7 Günümüz Türkçesi: “Gel, bu hikâyeyi yaz da bu eski bahçeyi tazeleyiver!” (Doğan, 2010: 105).

8 Günümüz Türkçesi: “Ben bir harabeyi tamir etmeye talibim; Allah'ın izni ile bunu başaracağım” (Doğan, 2010: 83). 
planda iken bugün mevcut kahraman ve konuları (Türk kültür mirasını/Türk kültüründeki ideal insan tiplerini) farklı biçimlerde sunmak esastır. Kısacası teknolojik gelişmelerle birlikte "Hayal Perdesinden Beyaz Perdeye" geçilmiş, (Özdemir, 2008: 163) Türk sözlü ve yazılı edebiyatının aktarımında yeni yol ve yöntemler bulunmuştur. Leylâ ve Mecnun geçmişten bugüne bu kapsamda ele alınan, eklemeler ve çıkarmalarla sürekli canlı tutulan önemli bir kültürel bellek oluşturmuştur. Geçmişte efsaneden mesnevilere taşınan ıstırap yüklü aşk teması, günümüz popüler kültür ortamında başta halk hikâyesi ve romanlar olmak üzere tiyatrolara, şiir kitaplarına, şarkılara, fikralara, karikatürlere konu olmuştur. Bu kapsamda Divan edebiyatında mesnevi yazan şairler gibi Türk edebiyatının hemen her döneminde yazarlar romanlarında Leylâ ve Mecnun'u aşka emsal göstermişlerdir. Bazen de bizzat Leylâ ve Mecnun'u roman, hikâye, tiyatroya ve şiire taşımışlardır. Türk edebiyatında Ahmet Özdemir, Hüseyin Bayçöl, Mehmet Karaman, Aziz Nesin, Reşat Nuri Güntekin, İskender Pala vb. birçok şair ve yazar, çeşitli eserlerinde Leylâ ve Mecnun aşkını işlemiştir.

Türk edebiyatında bir tema olarak Leylâ ve Mecnun çeşitlenmelerine oldukça sık rastlanmaktadır. Bu eserlerin Divan, Halk ve Yeni Türk edebiyatlarında önemli bir geleneği temsil ettiği görülür. Mesnevilerden hareketle bilinirlik kazanan bu hikâye, halk arasında beğenilmiş ve buna bağlı olarak sözlü aktarımın bir ürünü olarak folklorik bir nitelik kazanmıştır. Bu bağlamda Leylâ ve Mecnun, halk hikâyesinin yanı sıra bilmecelerde, halk tiyatrosunda ve mâni, koşma gibi halk şiiri türlerinde de sıklıkla işlenmiştir (Şenocak, 2000: 40-50).

Neced Çölü'nde ortaya çıkan hikâye, Kays'ın (Mecnun) aşka düşmesi ve divane olması bağlamında kişiliği üzerine oluşmuştur. Halk hikâyesi ve diğer türlerde icra edilen Leylâ ve Mecnun temasının kaynağı büyük oranda Fuzulî”nin mesnevisidir (Alptekin, 2011: 274). Leylâ ve Mecnun teması halk hikâyesinde geleneksel bir karakter kazanmıștır. Hikâye çocuksuzluk, rüya motifi, bade içme, imtihan, sevgilinin başka biriyle nikâhlanması, âşığın sevgilisini aramasıyla ona kavuşmak yolunda geçirdiği mücadeleleri anlatmaktadır (Sakaoğlu, 1999: 134-154; Şenocak, 2000: 206-244).

Leylâ ve Mecnun'un hüzünlü aşkı mânilerde şu șekilde işlenmiştir: "Așk ile coşan Mecnûn / Leylâ'ya koşan Mecnûn / Hâlim görse ağlardı / Dağlara düșen Mecnûn"; "İri gözlerin elâ / Așkın bașıma belâ / Dillerde destan oldu / Ben Mecnûn'um sen Leylâ"; "Eller eller gül eller / Pamuk eller gül eller / Yiğit aşka düşende / Mecnûn diye gülerler" (Şenocak, 2000: 42). Karacaoğlan bir şiirinde "Oturmuş sevdiğim zülfünü tarar / Gönül Mecnûn olmuş Leylâ'yı arar" (Şenocak, 2000: 45) diyerek aşkı terennüm etmiştir. Abdürrahim Karakoç da Omzumda Sevda Yükü isimli şiirinde aşk hikâyelerine telmihte bulunan şairler arasındadır: "Yorulup demedim yeter / Hasretin gözümde tüter / Kerem'den Mecnun'dan beter / Çöllerde seni aradım" (URL-3). 
Reşat Nuri Güntekin, Leylâ ile Mecnun'da çerçeve hikâye tekniğiyle aşkın vuslat ile hasret arasındaki konumunu Ziya ve Vesime karakterleri üzerinden yansıtmaktadır. Hikâyede Ziya evli olan Vesime karakterine platonik anlamda âşıktır. Ancak Ziya için Vesime, Leylâ'ya teşbihle kusursuzluğun timsali olarak görülmektedir. Ancak Vesime gerçekte Leylâ kadar saf ve temiz değildir. Hikâyede Mazhar Bey, Leyla'nın (Vesime) gerçek yüzünü yeğenine gösterme çabası içerisindedir. Hikâyede söz konusu platonik aşkın mizahi bir üslup çerçevesinde sonlandırılması anlatılmaktadır (2007: 5-11).

Aziz Nesin, Leyla ile Mecnun adlı eserinde konuyu Fuzulî'nin eserinden hareketle hikâye tarzında yeniden ele almıştır. Hikâye çocuksuzluk motifi sonrasında Aslan'ın (Mecnun) mucize doğumu ile başlamaktadır. Aslan ile Leyla okulda tanışır ve birbirlerine âşık olurlar: “...Kızlardan biri, bir peri, Aslan'la ilgilendi. Aslan da o periye ilgi duydu... Birbirlerine tutuldular. İstek sarhoşluğuyla ikisi de bir kadehten zevk şarabını içtiler" (Nesin, 2013: 9-10). Aslan'ın Leylâ'ya duyduğu aşk onu Mecnun eylemiştir.

İskender Pala tarafından yazılan Leylâ ve Mecnun romanının içeriği biçimsel açıdan Fuzulînnin mesnevisine benzemektedir. Roman, (Bir Doğuşta Dörtnala, Ad Koydular Çocuğa: Kays, 2 Lam + 2 Ya = Leylâ, Mecnun-ı Leylî = Leylâ'nın Çılgını...) on dokuz bölümden oluşmaktadır. Ayrıca romanda mesneviden alınan minyatürlere de yer verilmiștir (Pala, 2010). Roman, halk hikâyesi geleneğinde olduğu gibi çocuksuzluk motifinden hareketle mucizevi doğum olayıyla başlamaktadır. “...Öyle ya, nice seherlerde dilediği, nice türbelerde adadığı, nice seferlerde aradığ $ı$ oğul idi bu. Basra'dan Bağdat'a, Kufe'den Dımışk'a, Peygamber yurdu Mekke'den kutsal belde Yesrib'e, üçler, yediler, kırklar, pirler aşkına, nice uluların nefesleriyle ve himmetleriyle Allah'tan istediği, umduğu oğul idi bu" (Pala, 2010: 5). Yine İskender Pala tarafından yazllan, yönetmenliğini ise Ali Taygun'un yaptığ 1 Leylâ ve Mecnun oyunu İstanbul Şehir Tiyatrosu sahnesinde yeniden can bulmuştur. İskender Pala'nın yazdığı bir başka eser de "Babil'de Ölüm İstanbul'da Aşk" romanıdır. Bu eser de esas itibariyle Leylâ ve Mecnun romanıdır. Romanın kurgusu Fuzulî'nin kaleminden dökülen aşk hikâyesinin yazılış serüveni üzerine kuruludur.

Burak Aksak, Leylâ ile Mecnun konusunu mizahi bağlamda roman olarak işlemiştir. Roman, Leyla ile Mecnun efsanesine kurgusal göndermeler yapmakla birlikte popüler kültür ürünü olarak hazırlanmıştır. Hikâyenin girişinde bir çocuksuzluk motifi yerine Mecnun'un kahvaltıya uyandırılması söz konusudur. "Mecnuuun! Hadi annem kalk sofra hazır!" (Aksak, 2018: 11). Leylâ ve Mecnun'un kaderleri aynı gün yazılmıştır. İkisi de aynı arabada doğuma gitmiş, aynı hastanede dünyaya gözünü açmıştır. "Çok mu eski tanışıyorsunuz siz Metin Amca'yla? Sen doğduğun gün tanıştık. Eve bi' geldim, komşular 'Pakize doğuruyo!' dedi. Hastaneye götürmek için apar topar çıktım yola. Yolda bu el etti. 'Duramam', dedim, 'hastaneye yetişcem 
karım doğuruyo'. 'Benim karım da doğuruyo,' dedi atladı arabaya...” (Aksak, 2018: 87).

Romanda aşka, özleme ve şikâyete karşıllk olarak Mecnun karakterinin ağzından Ferdi Tayfur şarkılarına da yer verilmiştir. Romanda Mecnun, Leylâ'ya olan aşkından kendisini çöllerde bulmuştur: “Allaaah'ımmm nerdeyim ben? Çöldesin evlat. Allah'ım? Bu kadar çabuk dönmeni beklemiyordum, doğrusu. Hayır, dönmeni de beklemiyordum. Öldüm mü şu an ben?" (Aksak, 2018: 31-32). Halk hikâyelerinde âşık rüyasında hızır, pir, derviş elinden bade içerek sade kişilikten sanatçı kişiliğe geçer. Rüyada âş̧ı̆a sevgilisi gösterilir veya birbirlerinin ellerinden bade içerler. Bu anlamda romanda ak saçlı ve sakallı dede, Mecnun'a yardımcı olarak sunulmaktadır. "Belli ki âşık olmuşsun evlat. Çaresiz âşıkların son durağıdır burası. Sevdiğine kavuşursan meşk, kavuşamazsan aşk olur. Kavuşamayan âşıklar bu çölde ararlar sevdiğini" (Aksak, 2018: 32).

Leylâ ve Mecnun aşkı imkânsızdır; Leylâ, Mecnun'a yakınlaştıkça şimşekler çakar, gök gürler, depremler yaşanır, hava sıcaklı̆̆ı normalin üzerinde yükselmektedir. Leylâ bir anlık arzu ile Mecnun'u öpmüş ve büyük bir deprem yaşanmıştır. Ancak Mecnun bu durumu şu şekilde değerlendirmektedir: "Amaaan be dede. Atın ölümü arpadan, Mecnun'un ölümü Leylâ'dan olsun nedir yani?” (Aksak, 2018: 164). Romanda absürt mizah unsuru olarak ak saçlı ve sakallı dede tipi, dünyanın kaostan kurtulması için Mecnun ile Leyla'nın kavuşmasına engel olmaktadır.

Sezai Karakoç Leylâ ile Mecnun hikâyesini şiir dilinde yeniden yazan şairlerdendir. Bu eserde hikâye "Yolların Getirdiği, Doğum, İkiz Alınyazısı, Çölde Kurtarışlar Dönüşür Kurtuluşa, Ölüm ve Ötesi Ebedi Diriliş̧" başlıkları altında ele alınmıştır. Karakoç, Leylâ'nın doğumunu şu dizelerde ele almıștır: "Çiğ düştü göklerden / Ve bir bahar günü doğdun sen / Güvercinler geçti menekşelerden / Ve bir bahar günü doğdun sen... Baharın ta kendisi oldun sen" (2017: 15-17). Leylâ, Mecnun için baharın müjdecisi olmuştur. Hikâyeye göre Kays, Leylâ'nın aşkından, ona kavuşamamanın azabından Mecnun olup çöllere düşmüştür. Karakoç, 'Ninni' adı verilen bir şiirinde çölle ilgili şu dizeleri yazmıştır: "...Unutma çöl ulu bir şehirdir... Çöl bana mahsus bir şehirdir... Çölden geçmek Leylâ'ya ermek içindir” (2017: 21-22). Çöl, Leylâ'lara kavuşmak uğruna kendinden vazgeçen Mecnun'ların evidir. Çünkü gerek Leylâ gerek Mevlâ vuslatı çölden geçmektedir. Çünkü Mecnun için vuslat sadece bu dünya ile sınırı değildir. "Leylâ'dan öteye gidilmez ki / Leylâ Kafdağı ve Çin Seddi / Leylâ ötesinde meleklerin bile yandığı / Son sınırlar ülkesi / Yaradılışın sonu ondan ötesi / Leylâ, ölümüne susamış / Birinin içmesi gibi / Son yudumu bardaktaki / Leylâ bir kaynak gibi / Kim kurutabilir içerek / Çöllere hükmeden suları bir kaynaktaki" (Karakoç, 2017: 58). Sembolik anlamda Kays'ı Mecnun eden Leylâ imgesi, aşk anlatıları bağlamında bir anlamda vuslata duyulan hasret olarak asırlardır yaşatılmıştır. Dolayısıyla önemli olan vuslat neşesi ve heyecanı değil; hasretin ıstırabı ve hüznüdür. 
Leylâ ve Mecnun hikâyesinin önemli icra bağlamlarından birisi de sahnedir. Azerbaycan asıllı Türk sanatçı Üzeyir Hacıbekof tarafından bestelenen ve ilk gösterimi 25 Ocak 1908 tarihinde Bakü'de Hacı Zeynelabidin Tağıyevin tiyatro binasında yapılan opera da son derece önemli bir içerik olarak Leylâ ve Mecnun kültürel belleğinde kendine yer bulmuştur (URL-4). Ayrıca hikâye Bursa Şehir Tiyatroları tarafından "geleneksel hiciv" tarzında ele alınmıştır. Oyun Karagöz'den yola çıkılarak E. Ertan Akman tarafından adapte edilmiștir. Tüm klasik Ortaoyunu ve Karagöz oyunlarında olduğu gibi bu unutulmaz aşk hikâyesi, Karagöz'ün gözü ile irdelenmekte ve hicvedilmektedir (URL-5).

\section{Dijital Kültür Ortamında Leylâ ve Mecnun}

Leylâ ve Mecnun, bașta edebiyat eserleri olmak üzere medyanın da en zengin kaynaklarından bir tanesi haline gelmiştir. Divan edebiyatında Leylâ ve Mecnun yazan şairler gibi, modern edebiyatta da şair ve romancılar bu konuyu işlemekten geri kalmamışlardır. Âşık edebiyatında âşılar ve meddahların en çok anlattığı hikâyelerden birisi de Leylâ ve Mecnun'dur. Hikâyenin devrin ihtiyaç ve beklentilerine uygun olarak radyo, tiyatro ve sinemada işlenmesi geleneğin sürekliliği açısından son derece önemlidir. Bu anlamda popüler kültürün seçerek tükettirme algısının bir sonucu olarak Leylâ ve Mecnun çeşitlenmeleri ortaya çıkmıştır. "Gerhard Schulze'ye göre bugünkü insanın ana sorunu artık sınırlanmak değil seçmektir" (Aytaç, 2005: 14). Öyle ki bugünün okuyucusu, okumakla yetinmeyip hem dinlemeyi hem de izlemeyi tercih etmektedir. Kerem ile Asl, Arzu ile Kamber, Tahir ile Zühre hikâyelerinde olduğu gibi popüler edebiyatın en bilinen romanlarını da hem okuyabilir hem dinleyebilir, hem de izleyebilir. Bugünün okuyucusu Leylâ ve Mecnun'u sadece mesneviden okumakla yetinmez/yetinmek zorunda değildir, âşıklardan ve radyodan hikâyeyi dinleyebileceği gibi sanatçıların bu aşka yazdığı şiirleri ve şarkıları da dinleyebilir; tiyatro, sinema ve televizyonda izleyebilir. Kitle iletişim araçlarının gelişimiyle birlikte bir yazarın eserlerinin yalnızca kitapları olmadığı görüşü yaygınlaşmaya başlamıştır (Aytaç, 2005: 15).

Divan şiirinde daha çok tasavvufi boyutuyla tanışılan efsanevi aşk öyküsü, popüler edebiyatta maddi aşka doğru bir yöneliş takip etmiş ancak tasavvuftan tamamen sıyrıl(a)mamıştır. Onun özündeki tasavvuf olgusu kara sevda motifi olarak korunmuştur. Sinemadaki yansıması da hemen hemen buna benzerdir. Bu yapımlardan ilki 1972 yılında (Film: 1) Cahit Erkin ve Duygu Sarıoğlu'nun yönettiği Kadir İnanır ve Fatma Girik'in başrollerini paylaștığı Leylâ ve Mecnun'dur. Âșık Veysel'in “Uzun İnce Bir Yoldayım" fon müziğiyle başlayan filmde Kadir İnanır, Ali (Mecnun) Fatma Girik ise Leylâ rolünde oynamaktadır. Film, aynı çölde yaşayan Ali ve Leylâ'nın koyun sürüsü önündeki görünümüyle başlamaktadır. Âşıklık geleneğinde sade kişilikten sanatçı kişiliğe geçişte en çok vurgulanan meslek çobanlıktır. Âşık genellikle fakir bir ailenin çocuğudur ve geçimini koyun sürülerini otlatarak sağlamaktadır. Filmde koyun sürüsüne yer verilmesi 
bununla ilgilidir. Kucağında bir ceylan, elinde bir sazla bir anda çölde beliren bir ihtiyar, elindeki sazı Ali'ye, ceylanı da Leylâ'ya verir. Aslında bu Âşık edebiyatındaki bade içmenin bir türüdür. Bade somut anlamıyla bir içecek değil bazen bir yiyecek veya sembol de olabilmektedir (Günay, 2011: 127137). Ali saz çalmayı bilmediğini söyleyince tez zamanda öğreneceksin der ve elindeki asayı yere vurur. Bu hareket çöl topraklarını yeșertecek "Âşıklar Pınarı”nı topraktan fışkırtarak Ali ile Leylâ'nın efsanevî aşkına nişan koyar. Buradaki pınar bade yoluyla rüya motifini hatırlatmanın ötesinde âşılkların imgesel dünyada yaşadığı vuslatın tecellisidir.

Ali ile Leylâ amca çocuklarıdır. Leylâ'nın babası büyük kardeş olduğu için ülke yönetimini üstlenir. Ali'nin babası da geçim kaynaklarının yetersiz olduğu bahanesi ve bir ülkede iki beyin olamayacağı gibi gerekçelerle ülkeden gönderilir. Ali ile Leylâ bu anlaşmazlık sonucu çocuk yaşta birbirinden ayrılır. Aradan uzun zaman geçer, ayrı diyarlarda büyüseler de aşklarından vazgeçmezler. Leylâ bu ayrılığa daha fazla katlanamaz ve ceylanına Ali'yi bulup getirmesini söyler. 0 sıralarda avda olan Ali ceylanı görür ve peşine takılıp Leylâ'ya gelir. İlk başta birbirlerini tanımayan âşıklar konuşurlar (URL-6)

"Ali: “...Yıllar önce küçük bir ceylanı olan bir kız tanırdım, onu soracaktım sana. Leylâ: Dur yabancı, ceylanından başka nesini hatırlıyorsun, o kızın? Ali: Ömrümde onun kadar mavi gözleri olanı görmedim bir daha, upuzun simsiyah saçları vardı, şimdi söylesem gülersin bana, sazıma tel yapmak isterdi, saçlarından. Leylâ: Sen de ona yeminler eder miydin? Ali: Ederdim, ondan başka kimse için saz çalmayacağıma yemin ederdim, gönülden. Leylâ: Yeminlerini tuttun mu? Ali: Tuttum, ömrüm oldukça da tutacă̆ım. Leylâ: Bu kadar siyah mıydı, saçları? Ya gözleri bu kadar mavi miydi?" (URL-7)

Âşık geleneğinde imtihan önemli bir motiftir, âşıklar çeşitli sorularla birbirlerini sınarlar. Çocuk yaşta birbirinden ayrılan âşıkların ya da beșik kertmesi sevdalıların birbirlerini sınamaları halk hikâyelerinde tekrar eden bir motiftir. Dede Korkut Kitabında, Kam Püre Oğlu Bamsı Beyrek Boyu'nda Beyrek, av esnasında bir geyiğin peşinden Banu Çiçek'in otağına gelir. Banu Çiçek Beyrek'le tanışmak için “at yarıștırma, ok atma ve güreş”ten oluşan çeşitli yarışmalar yapar. Yarışmalar neticesinde Bamsı Beyrek ile Banu Çiçek birbirlerini tanırlar (Ergin, 2004: 122). Leylâ ve Mecnun filminde de birbirlerini tanıyan Ali ve Leylâ, cariye Reyhan'ında yardımlarıyla bundan sonra gizli gizli görüşmeye başlarlar.

Âşık hikâyelerinde âşıklar çile yüklü sevdalarını sazlarıyla terennüm ederler. Filmde Ali'nin çeşitli türküler okumaktadır: "Doya doya bakamadım / Gök mavisi gözlerine / Bir gün başım koyamadım / O Leylâ'mın dizlerine; Gönlümde kalamadı karar / Gözlerim Leylâ'mı arar / Ben Leylâ'dan ayrılalı / İçimde bir ateş yanar". Aşk konulu hikâyelerde (Âşık Garip gibi) sadece âşıklar değil maşuklarda saz çalıp şiirler terennüm ederler. Leylâ ve Mecnun filminde bu konu da işlenmiştir:

Şekerden baldan tatlıdır

Leylâ'm senin dilin bana 
Damarımda kanımsın sen

Canım kurban Leylâ'm sana (Mecnun)

Ayrilığın ateşten ok

Senden gayrı sevdiğim yok

Dünya dünya diyorlar oy

Senden başka bir dünyam yok (Leylâ)

Ne gecenin mehtebinda

Ne gündüzün güneşinde

Ne Yusuf u Züleyha'da

Sende olan güzellik yok (Mecnun)

Ben peteğim sen balımsın

Ben ağacım sen dalımsın

Sen olmazsan yaşayam

Damarımda sen kanımsın (Leyla), (URL-8).

Âşıkların âşık olmaları gibi kavuşmaları, ayrılmaları ve kara toprakla kucaklaşmaları da birtakım anlamlar taşır. Bu yapımda son nefesini veren Leylâ'nın duası şu şekildedir: "Pınar, aşkımızın ölümsüz şahidi kutsal pınar, beni anlayan, acıma ortak olan pınar, dilerim Allah'tan bu su çağıldayıp aktıkça türkümüz çalınsın, aşkımız anlatılsın, ebediyete kadar, kıymasınlar sevişen gönüllere, ayırmasınlar birleșen kalpleri, kurumasın dallarda goncalar, tomurcuklanmış aşklar hiç solmasın”. Leylâ'nın ölümüyle kendini kaybeden Ali de "Murada eremedik Leylâ'm, ömrümüzce ağladık ikimizde, sen yoksun artık, ben de yoktan beter, gülmedik hiç bu yalan dünyada, güldürsün orda kadir Mevla, unutulmasın aşkımız, yazısın” demiştir. Leylâ ve Mecnun hikâyesini konu edinen film, Ali'nin terennüm ettiği "Feda etti canını Leylâ benim uğruma / Merhamet eyle ya Rab Leylâ Mecnun kuluna" (URL-9) dizeleriyle son bulur. Leylâ, Ali ile aşklarının ölümsüz sembolü olan ve Hızır'ın onları nişanladığı pınar başında can verir. Filmde halk hikâyeciliği geleneğine ait unsurların oldukça sık biçimde işlendiği görülmektedir.

Bu yapımdan on yıl sonra 1982 yılında (Film: 2) Halit Refiğ tarafından yönetilen başrolde Orhan Gencebay ve Gülşen Bubikoğlu'nun yer aldığı Leylâ ve Mecnun filmi gelir. Bu filimde Leylâ efsanedeki adını korurken Mecnun'a Kadir ismi verilmiștir. Leylâ ve Kadir aynı gün doğan ve kaderleri birbirlerine yazılan iki aşk ehlidir. Leylâ ve Kadir tüm çıkmazlara rağmen birbirlerini sevmekten vazgeçmezler. Onlar Derviș aracılığıyla çocukluktan sevdaya gark olmuşlardır. Âşıkların vuslatı hikâyedeki kurgudan dolayı mümkün değildir. Leylâ, aşkı için taşlanarak öldürülmüştür. Kadir'in aşkı ise daha çilelidir, o sevdası uğruna doğuştan yetim büyümüş, Leylâ'nın babası tarafından öldürülmek istenmiş, esir düşmüş, köle pazarında satılmış ve gözlerine mil çektirilmiştir (URL-10). 
Filmin kurgusu Hz. Musa'nın yaşam hikâyesini hatırlatmaktadır. ${ }^{9}$ Leylâ ve Mecnun filmindeki kurgu da bu kıssaya dayanmaktadır. Kadir, Leylâ'nın babası Şeyh Gaffar'ın zulmünden kurtulmak için bir sal üzerinde nehre bırakılır. Kadir, Şeyh Gaffar'ın veziri tarafından en has adamı olarak büyütülür. Bu yönüyle Hz. Musa'nın yaşam öyküsüne telmihte bulunulduğu söylenebilir.

Her iki filimde de birtakım ortak motifler bulunmaktadır. Filmlerin hikâyeleri karşılaștırdığında vuslatın önündeki en büyük engel Leylâ'nın ailesinden kaynaklı olduğu görülür. Her iki film de vuslatla sonuçlanmaz. İlk filmde (Film: 1) derviş, kutsal su, ceylan hikâyeye anlam kazandıran motiflerdir; ikinci filmde ise derviş yerini korurken kutsal su yerini hurma ağacına bırakırken ceylana bir karşılık bulunamamıștır. Leylâ ve Mecnun filminin ilk yapımında Leylâ zehirli iksir içerken ikincisinde de iksir içmek ister; ama Kadir'in okuduğu şarkı onu bu istekten vazgeçirir. Bilindiği gibi çileli aşk öykülerinde türküler önemli bir yer tutmaktadır. İlk filimde Mecnun rolündeki Ali, saz çalıp türküler okurken ikinci filimde Mecnun rolünde oynayan Kadir saz olmaksızın şarkılar söylemektedir. İlk filimdeki Leylâ, Ali'ye karşıllk türküler söylerken ikinci filimde böyle bir durum söz konusu değildir. Ama buna rağmen özellikle ikinci filimde şarkılar, arabesk bahçesinden bir demet çiçek misali okunur. Her iki filmde de dansöz oynatma, eğlencelerin vazgeçilmez unsurudur. Söz konusu durum dönemin popüler kültürüyle alakalıdır.

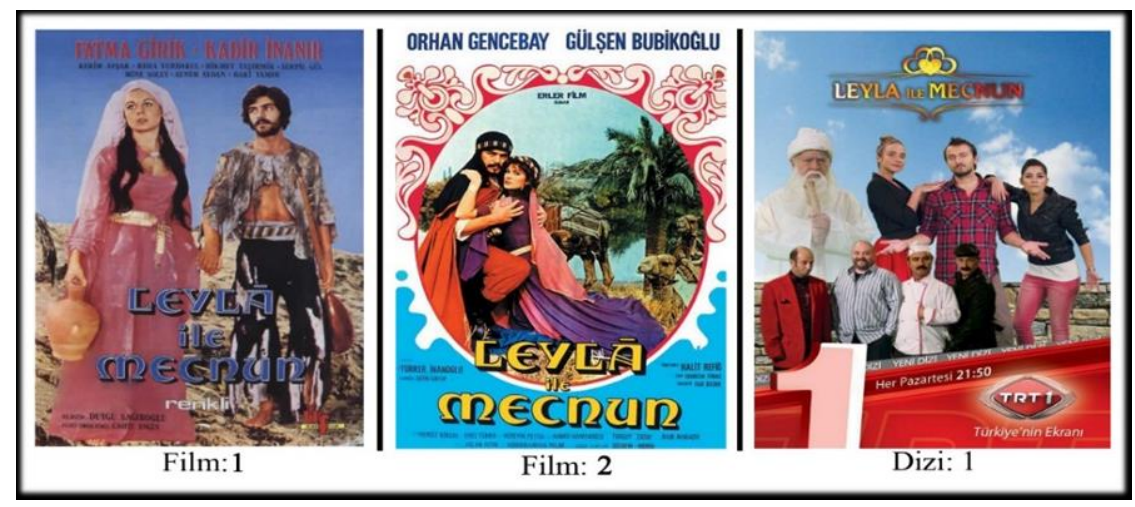

Resim 1: Leylâ ve Mecnun örnekleri (URL-17).

Leylâ ve Mecnun filmler dışında TRT'de üç sezon boyunca yayınlanan (Dizi: 1) absürt komedi dizisine de konu olmuştur. Leylâ ve Mecnun, 9 Şubat 2011 ila 12 Haziran 2013 tarihleri arasında yayınlanan, senaryosunu Burak Aksak'ın, yönetmenliğini ise Onur Ünlü'nün yaptığı 103 bölümlük bir dizidir.

\footnotetext{
${ }^{9} \mathrm{~Hz}$. Musa'nın doğduğu zamanlarda Firavun bütün erkek çocukları öldürtmektedir. Hz. Musa da bir sandık içerisinde Nil Nehri'ne bırakılarak Firavun zulmünden kurtulmuştur. Ancak Hz. Musa'nın yaşam öyküsünü ilginç kllan onun, Nil Nehri'nde bulunduktan sonra Firavun'un eşi Asiye tarafından sahiplenilmiş ve Firavun sarayında büyütülmüş olmasıdır (ULR-11).
} 
Birtakım gerekçelerden dolayı dizi final yapmadan yayından kaldırılmıștır (URL-12). Leylâ ve Mecnun dizisi, genel kurgusu itibariyle halk hikâyesi giriş kalıbıyla başlamaktadır. Dizi "çağdaş hayatta ve kent ortamındaki çeşitli karakterlerin yaşantıları bağlamında ilerlemektedir. Bazı bölümlerde dizi karakterlerinin uzaya çıkması, yer altına yolculuk yapması, çeşitli tarihî dönemlerde gezinmesi, meydan savaşlarına katılması, Dostoyevski'nin evlerine konuk olması vb. gibi, zaman ve bağlam dışı ögelere sıklıkla yer verilmiștir" (Keskin, 2016: 47).

Aynı hastanede dünyaya gelen Leylâ ve Mecnun, hastanedeki beşikler dolu olduğu için aynı beşiğe konulmaktadır. Çocukların babaları da bu durumun bir kader olduğunu düşünerek çocuklara Leylâ ve Mecnun isimlerini koyarlar. Aradan geçen zamanda Leylâ ve Mecnun hiç görüşemez. Mecnun ve ailesi Leylâ'yı istemeye gider; ama Leylâ evde yoktur. Bu durum Mecnun'un ailesi tarafından yanlış yorumlanır ve aileler arasında tartışma çıkar. Leylâ'nın ailesi kızlarını Mecnun gibi fakir, işsiz güçsüz bir adama layık görmedikleri için vermek istemez. Onlara göre Leylâ sadece Arda gibi zengin ve karizmatik bir gençle evlenebilir. Mecnun'un ailesi evi terk ederken Leylâ gelir. Mecnun beşik kertmesini ilk kez görür ve hemen âşık olur. Dizinin ilk bölümünde aksiyon bu konu üzerine kurulmuștur. İlk görüşte aşk Mecnun'u kendinden geçirir, rüyasında çöllere düşen Mecnun kimi zaman kâbuslar kimi zaman da Leylâ'sını görür. Çölde ayrıca bir ihtiyarla karşılaşır. Bu ihtiyar Mecnun'a Leylâ'ya ulaşabilmesi için birtakım nasihatlerde bulunur. Mecnun'un rüyasında gördüğü aksakallı ihtiyar o gece Mecnun'ların evine yerleşir. Ayrıca dizide çöl, ev, taksi ve bakkal dükkânı en önemli mekânlardır. Yine ilk bölümde Mecnun, Ferdi Tayfur'un "Olsan İçmez miydin Benim Yerimde?" şarkısı eșliğinde kederlenmektedir: "Baharım solmadan eskidi ömrüm / Çıkmaz bir sokağa benzedi ömrüm / Leylâ'sı olmayan Mecnun'a döndüm / Olsan içmez miydin benim yerimde" (URL-13). Bu dizi tarz itibariyle diğer Leylâ ve Mecnun yapımlarından ayrılır. İzleyici dizide sıradan bir yaşantının saçmalıklar, tesadüfler ve aşk temasıyla yoğurulmuş bir sunumuyla karşılaşır. Dizide geleneksel anlatıda yer alan bazı önemli tip ve motifler olduğu gibi ya da değiştirilerek yer almaktadır. Derviş, ihtiyar, ak saçlı ve sakallı tipi, at tipi, alnından öperek uyandırma (masal motifi), rüya motifi vb. bu absürt komediye eşlik eden tip ve motifler olarak sunulmuştur.

Leylâ ve Mecnun, Radyo Tiyatrosu kapsamında yazarlı̆̆ını ve yönetmenliğini Mehmet Köseoğlu'nun, seslendirme yönetmenliğini ise İskender Bağclar ve Neslihan Gürgün'ün yaptığı TGRT FM yapımı 15 bölümlük "Arkası Yarın Kuşağı" şeklinde bir radyo oyununa konu olmuştur (URL-14). Bu içeriklerin tamamı Leylâ ve Mecnun, anlatım ve gösterim geleneğinin bir yansıması olarak değerlendirilebilir.

Leylâ ve Mecnun aşkı -özellikle aşk konularında- karikatüristlerin de çok sık başvurduğu kaynaklar arasında yer alır. İmkânsız olan her şey mizah üzerinden Leylâ ve Mecnun aşkına telmihle sunulmaktadır. 

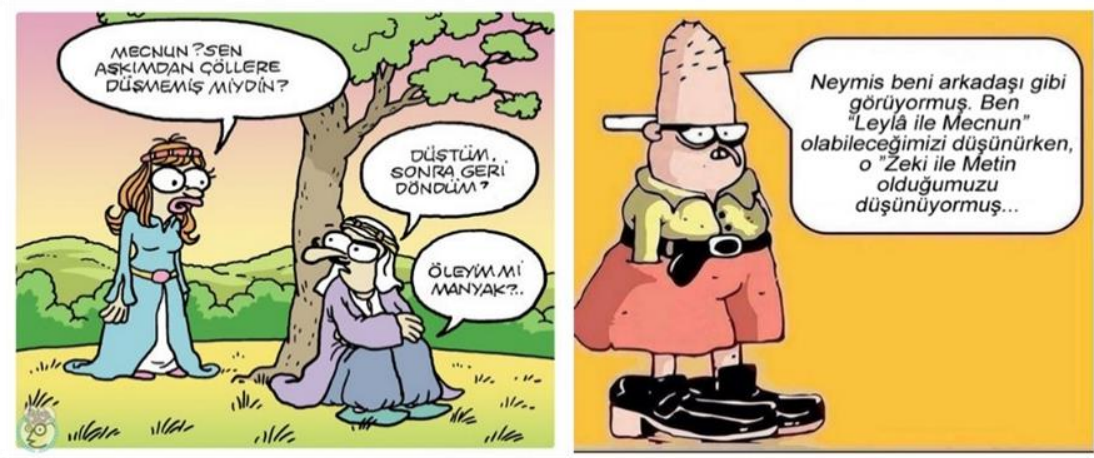

Resim 2: Leylâ ve Mecnun karikatürlerinden örnekler (URL-17).

Türk kültürü mizah açısından da oldukça zengindir. Başta fikralar olmak üzere son yıllarda karikatür edebiyatı da bu sahada önemli roller üstelenmektedir. Gelenek kimi zaman olduğu gibi kullanılırken kimi zaman da sadece tema bakımından kullanılmaktadır. Karadeniz'in fikra tiplerinden olan Temel ve Fadime'yle Leylâ ve Mecnun konulu kısa ama öz bir fıkra oluşturulmuștur. Bu bağlamda Leylâ ve Mecnun, Karadeniz fikralarına da konu olmuştur: Temel eşi Fadime'yle birlikte tiyatro gișesine gitmiştir. Gişedeki görevliye: "Bize içi bilet lütfen" demiştir. Gişe görevlisi: "Leyla ile Mecnun için mi?" diye sorduğunda Temel: "Hayır Fadime'yle benum için" demiştir (URL-15). Türk fikra belleği kapsamında Temel ile Fadime, Karadeniz'in Leylâ ve Mecnun'u olarak görülebilir.

Leylâ ve Mecnun âş̧ıların repertuvarında yer alan çeşitli türlerde; popüler müziklerde telmihle anılmıştır. Âşık Veysel'in “Mecnun'um Leyla'mı Gördüm” ile Yıldız Tilbe'nin "Leylâ Mecnun Aşk Görsün" söz konusu tematik içeriklere örnektir. Falım sakızları tarafından yayınlanan bir reklam içeriğinde Leylâ ve Mecnun arasında şöyle bir diyalog geçmektedir: "Mecnun: Leylâaaaaa! Leylâ: Git başımdan Mecnun, tipim değilsin. Mecnun: Leylâaaaaa! Misafir Oyuncu: 'Ya Mecnun, aç bir Falım rahatla'. Slogan: Aç bir Falım rahatla / Neler olur bak hayatta. Mâni: Mecnun olana / Leyla çok / Üzülme sana / Leyla mı yok. Başka Leylâ: Merhaba! Ben Leylâ. Mecnun: Leylâaaaaa! Slogan: Aç bir Falım rahatla / Neler olur bak hayatta" (URL-16).

Leylâ ve Mecnun'un imkânsız aşkları ve yaşadıkları telmihle anılanlar arasında yer almaktadır. Bu anlamda Leylâ ve Mecnun, gerek Divân şiirinde gerek diğer şiir türlerinde telmih yoluyla oldukça sık başvurulan konular arasında yer almaktadır. Fuzulî, "Bende Mecnûn'dan füzûn âșıklık isti'dâdı var / Âşık-ı sâdık benim Mecnûn'un ancak adı var (Tarlan, 1981: 275)" diyerek aşkta adı çıkan Mecnun'u aşarak daha yüksek mertebelere çıktığını vurgulamaktadır.

İnternet kültürel içeriklerin en çok tüketildiği kitle iletişim araçlarının başında gelmektedir. Bu anlamda internette bir içeriğin aranmasında en çok kullanılan Google arama motorunda yapılan taramalarda Leylâ ve Mecnun 3 milyon 960 bin; Leyla ile Mecnun 4 milyon 490 bin sonuç vermiştir. Bu 
sonuçlar içerisinde ilk on TRT yapımı dizi, ekşi sözlük, wikipedia, kitap siteleri, netflix ve diğer film siteleri içeriklerinden oluşmaktadır (URL-17). Söz konusu veriler Leylâ ve Mecnun'un gelenek ile gelecek arasında çok çeşitli kültürel içeriklere dönüşerek bir köprü vazifesi gördüğünü doğrulamaktadır.

Leylâ ve Mecnun bir hikâye olmanın dışında üzerinden geçen zamanla birlikte külte ve kültüre dönüşmüştür. Fuzulî’nin mesnevisinin son bölümünde belirttiği üzere Leylâ'nın ölümü üzerine Mecnun da mezara kapanarak canını teslim etmiştir. İki sevgili aynı mezara defnedilmiş ve burası adeta bir türbeye dönüşmüștür. Günümüzde hikâyenin bilinirliği, farklı formlarda ele alınması ve halen canlılığını koruması esasında bahsi geçen külte ve kültüre dönüșmeyle açıllanabilmektedir.

\section{Sonuç}

Türk kültürü anlatım ve gösterim gelenekleri açısından zengin bir birikime sahiptir. Bu kapsamda farklı coğrafyalarda teșekkül eden evrensel tema ve konular, Türk kültür ikliminin süzgecinden geçirilmek suretiyle millileştirilmekte ve Türk kültür belleğine yerleştirilmektedir. Evrensel bir tema ve konu olan Leylâ ve Mecnun'un Türk kültür coğrafyasında çok sayıda tür ve biçimde işlendiği tespit edilmiştir. Dolayısıyla Arap kaynaklı bir efsane olan Leyla ve Mecnun, Türk kültür ikliminde kendisine özgü ve özgün bir kültürel mirasa dönüşmüştür. Çalışmada Leylâ ve Mecnun efsanesinin türler arası geçişleri, sözlü, yazılı ve elektronik kültürler arası yaşanan dönüşümler, açlk bir şekilde ortaya konulmuştur. Bu kapsamda makalede Divan şiirindeki zenginliğiyle kendisine özgü bir birikim oluşturan Leylâ ve Mecnun hikâyesinin ikincil sözlü kültür boyutuyla çok sayıda kültürel ve ekonomik çıktıları olduğu görülmüştür. Çalışmada öncelikle edebiyat eserlerinin medya kapsamında yeniden üretimi konusuna değinilerek bu kapsamda Leylâ ve Mecnun hikâyesi sorgulanmıştır. Sonuç olarak geçmişten bugüne zengin bir kültürel bellek unsuru haline gelen Leylâ ve Mecnun efsanesinin, öncelikle hem geleneksel hem de modern edebiyatın önemli kaynakları arasında olduğu ortaya konulmuștur. Ayrıca Leylâ ve Mecnun konusunun radyo, sinema ve televizyon bağlamında oyun, film, dizi, reklam, müzik, skeç, karikatür, mizah vb. türlerde popüler yaşamın ayrılmaz bir tüketim ürünü olarak varlığını sürdürmeye devam ettiği görülmüştür.

\section{KAYNAKÇA}

\section{Yazılı Kaynaklar}

Aksak, B. (2018). Leylâ ile Mecnun, İstanbul: Küsurat.

Aktulum, K. (2013). Folklor ve metinlerarasıllk, Ankara: Çizgi Kitabevi

Alıç, F. (2011). Halk hikâyeciliğinde yeni icra ortamı olarak sinema ve sinemaya uyarlanan Türk halk hikâyeleri. İstanbul: İstanbul Üniversitesi Sosyal Bilimler Enstitüsü Yayımlanmamış Yüksek Lisans Tezi.

Alptekin, A. B. (2011). Halk hikâyelerinin motif yapısı, Ankara: Akçağ.

Aytaç, G. (2005). Edebiyat ve medya, Ankara: Hece Yayınları. 
Doğan, M. N. (2010). Fuzulî-Leylâ ve Mecnun, İstanbul: Yelkenli.

Ergin, M. (2004). Dede Korkut Kitabı-I. Ankara: Türk Dil Kurumu.

Günay, U. (2011). Türkiye’de âşık tarzı şiir geleneği ve rüya motifi. Ankara: Akçağ.

Güntekin, R. N. (2007). Leylâ ile Mecnun. İstanbul: İnkllap.

Karakoç, S. (2017). Leylâ ile Mecnun. İstanbul: Diriliş.

Keskin, A. (2016). Sevdiğin dizi gün değiştirsin: Leyla ile Mecnun dizisindeki kargışların (beddua) pragmatik analizi. Millî Folklor, S. 109, 44-57.

Nesin, A. (2013). Leyla ile mecnun, İstanbul: Nesin.

Ong, W. J. (2010), Sözlü ve yazılı kültür, sözün teknolojileşmesi. (Çev.: S. Postacıoğlu Banon), İstanbul: Metis.

Özdemir, N. (2008). Medya kültür ve edebiyat. Ankara: Geleneksel.

Özyön, A. (2013). Goethe'nin Genç Werther'in Acıları ve Mehmet Rauf'un Eylül romanlarında umutsuz aşk izleği. International Journal of Language Academy, 1/1 Winter, 23-38.

Pala, İ. (2010). Leylâ ile Mecnun. İstanbul: Kapı.

Pala, İ. (2011). Ansiklopedik divân şiiri sözlüğü. 20. b., İstanbul: Kapı.

Sakaoğlu, S. - Alptekin, A. B. - Sakaoğlu, Y. - Şimşek, E. (1999). Meddah Behçet Mahir'in bütün hikâyeleri-II, Ankara: Atatürk Kültür Merkezi Başkanlığı.

Şenocak, E. (2000). Leylâ ile Mecnûn hikâyesi üzerine mukayeseli bir araștırma. Elazı̆̆: Fırat Üniversitesi, Sosyal Bilimler Enstitüsü Yayımlanmamış Yüksek Lisans Tezi.

Tarlan, A. N. (1981). Fuzûlî divan şerhi. Ankara: Akçă̆.

Törenek, M. (1999). Hikâye ve romanlarıyla Mehmet Rauf. İstanbul: Kitabevi.

\section{Elektronik Kaynaklar}

URL-1: http://tr.wikipedia.org/wiki/Romeo_ve_Juliet (Erişim: 26.01.2020).

URL-2: http://tr.wikipedia.org/wiki/Dosya:Yasar-ne-yasar-ne-yasamaz-1974.jpg, (Erişim: 26.01.2020).

URL-3: http://siir.sitesi.web.tr/abdurrahim-karakoc/seni-aradim.html, (Erișim: 16.01.2020).

URL-4: https://tr.wikipedia.org/wiki/Leyla_ve_Mecnun_(opera), (Erişim: 15.12.2019).

URL-5: http://www.bursasehirtiyatrosu.gov.tr/leyla-ile-mecnun.html, (Erişim: 15.12.2019).

URL-6: Leylâ ile Mecnun (Film:1);

https://www.youtube.com/watch?v=lrdZ3wzlang. (Erişim: 25.01.2020).

URL-7: https://www.youtube.com/watch?v=lrdZ3wzlang, (Erişim: 05.01.2020).

URL-8: https://www.youtube.com/watch?v=lrdZ3wzlang, (Erişim: 25.01.2020).

URL-9: https://www.youtube.com/watch?v=lrdZ3wzlang, (Erişim: 25.01.2020).

URL-10: Leylâ ile Mecnun (Film: 2); http://www.yesilcamtv.eu/leyla-ile-mecnun1.html, (Erişim: 26.01.2020).

URL-11: https://islamansiklopedisi.org.tr/musa--peygamber (Erişim: 17.01.2020). URL-12: http://tr.wikipedia.org/wiki/Leyla_ile_Mecnun_dizi (Erişim: 15.02.2020). 
URL-13: $\quad$ Leylâ
https://www.youtube.com/watch?v=ABnP9ZeIc8E

URL-14: https://www.radyotiyatrosu.net/leyla-ile-mecnun (Erişim: 21.12.2019).

URL-15: http://www.fikracenneti.com/temel-fikralari/leyla-ile-mecnun-2-2

(Erişim: 29.122019).

URL-16: https://www.youtube.com/watch?v=ZRkzcfUyTyc (Erişim: 22.02.2020).

URL-17: www.google.com.tr (Erişim: 21.01.2020).

URL-18: Şentürk, S. (2012). Ekranın dizi dizi romanları. Milliyet Gazetesi, http://www.milliyet.com.tr/pembenar/ekranin-dizi-dizi-romanlari1212854 (Erişim: 26.01.2020). 